\title{
A BREVE HISTÓRIA DO POSITIVISMO DESCRITIVO. O QUE RESTA DO POSITIVISMO JURÍDICO DEPOIS DE H. L. A. HART?
}

A BRIEF HISTORY OF DESCRIPTIVE POSITIVISM. WHAT REMAINS OF LEGAL POSITIVISM AFTER H.L.A. HART?

BREVE HISTORIA DEL POSITIVISMO DESCRIPTIVO. ¿QUÉ RESTA DEL POSITIVISMO JURÍDICO DESPUÉS DE H. L. A. HART?

Thomas Bustamante ${ }^{1^{*}}$

1 Professor da Universidade Federal de Minas Gerais. Doutor em Direito pela PUC-Rio. Mestre em Direito pela UERJ. Esse ensaio é originado de pesquisa realizada com recursos financeiros provenientes do CNPq e da FAPEMIG, a quem o autor agradece pelo investimento realizado. 
Resumo: O positivismo jurídico, no sentido contemporâneo de teoria que sustenta as teses da separabillidade entre direito e moral e das fontes sociais do direito, se apresentava em suas origens mais como uma tese político-moral do que como uma descrição neutra, desengajada ou meramente conceitual do sistema jurídico. Esse sentido, no entanto, se perdeu no tempo e permanece ignorado nos escritos dos autores mais reconhecidos do positivismo dos últimos duzentos anos, como Austin, Kelsen e Hart. Pretende-se explicar, nesse ensaio, como as críticas de Dworkin à metodologia do positivismo desmistificam o denominado positivismo descritivo, de modo que o positivismo jurídico contemporâneo só pode ser aceito se ele for entendido como uma teoria normativa, no sentido originário em que Bentham compreendia a sua teoria do direito.

Abstract: Legal positivism, in its current understanding as a theory that upholds the theory of separability between law and morality and the social sources of law, is in its origins more as a political-moral theory than as a neutral, disengaged, or merely conceptual description of the legal system. But this original meaning has been lost over time, and is largely ignored in the works of the most prominent authors of the positivist tradition in the last two hundred years. In this essay, I attempt to explain how Dworkin's objections to the methodology of positivism demystify the so-called 'descriptive positivism', so that contemporary legal positivism can only be accepted if it is understood as a normative theory, in the original sense in which Bentham understood his legal theory.

Resumen: El positivismo jurídico, en el sentido contemporáneo de teoría que sostiene las tesis de la separabilidad entre derecho y moral y de las fuentes sociales del derecho, se presentaba en sus orígenes más como una tesis político-moral que como una descripción neutra, sin compromiso o meramente conceptual del sistema jurídico. Sin embargo, ese sentido se perdió con el tiempo y permanece ignorado en los escritos de los autores más reconocidos del positivismo de los últimos do- 
scientos años, como Austin, Kelsen y Hart. Se intenta explicar en este ensayo cómo las críticas de Dworkin a la metodología del positivismo desmistifican el denominado positivismo descriptivo, de modo que el positivismo jurídico contemporáneo solo puede ser aceptado si se lo entiende como una teoría normativa, en el sentido originario en el que Bentham comprendía su teoría del derecho.

\section{INTRODUÇÃO}

P ropõe-se, neste breve ensaio, situar historicamente o positivismo jurídico no contexto de sua formação, elucidando o processo histórico de diferenciação entre o positivismo jurídico e o jusnaturalismo a partir do marco temporal da filosofia jurídica de Jeremy Bentham. Por meio dessa contextualização, será fornecida uma explicação para a formação do denominado "positivismo descritivo", "analítico" ou "conceitual", cujo precursor foi o jurista inglês John Austin, principal pupilo de Bentham.

O texto exporá de forma crítica a trajetória e os fundamentos filosóficos do positivismo descritivo, bem como a sua radicalização na Teoria Pura do Direito de Kelsen e na obra jurídico-filosófica de H.L.A. Hart. Como problema de pesquisa se pretende indagar se e em que medida o positivismo descritivo ou metodológico, que constituiu o approach dominante ao longo dos últimos duzentos anos, consegue resistir às críticas metateóricas desenvolvidas por autores como Ronald Dworkin e outros teóricos contemporâneos.

A hipótese central que se procura provar por meio dessa análise histórica é de que a teoria jurídica de Hart, ao atrair a atenção para o denominado "ponto de vista interno", contém o germe para a destruição do ontologismo essencialista que caracteriza as teses filosóficas do positivismo descritivo, já que este ponto de vista (interno) reclama uma abordagem hermenêutica do filósofo do direito. Essa abordagem, como se sustentará nas próximas páginas, torna insubsistente o método de investigação proposto pelo positivismo descritivo de Austin e Kelsen e pelo próprio Hart. 
O objetivo do presente ensaio é fundamentar essa hipótese, bem como a tese de Dworkin de que o positivismo jurídico só encontra condições de se sustentar se ele for relido, deixando de ser uma teoria semântica para se tornar uma concepção teórica acerca do direito, é dizer, uma teoria tão normativa e interpretativa quanto as teorias não positivistas com as quais ele se defronta.

A única alternativa para o positivismo jurídico no cenário contemporâneo é, por conseguinte, tornar-se um "positivismo normativo" no sentido de Waldron e Campbell, os quais propõem uma teoria neo-benthamista que rejeita expressamente as premissas da filosofia do direito de corte puramente analítico.

Nas seções seguintes, pretende-se demonstrar essa conclusão, partindo inicialmente de uma comparação, na seção 2, entre as ideias jurídicas de Bentham e Austin no contexto da formação do denominado positivismo "metodológico" ou "descritivo". Após descrever as diferentes perspectivas metateóricas desses autores, este ensaio aborda ainda a radicalização do positivismo descritivo em Kelsen, na seção 3, e a denominada "virada hartiana" para o ponto de vista interno, na seção 4.

Essa reflexão sobre a modernização do positivismo abrirá caminho para a crítica de Dworkin, que será tratada na seção 5, e para o ocaso do positivismo descritivo e o renascimento do positivismo normativo, que estava adormecido desde Bentham, mas hoje está cada vez mais forte. É com uma breve alusão a esse renascimento do positivismo normativo que se conclui o presente ensaio.

\section{O POSITIVISMO NORMATIVO E O POSITIVISMO DESCRITIVO NO SÉCULO XIX: A PASSAGEM DE BENTHAM A AUSTIN}

Pode-se dizer que o positivismo jurídico, no seu sentido contemporâneo, somente conseguiu se consolidar com a teoria jurídica de Jeremy Bentham, que teve o grande mérito de trazer as discussões acerca da natureza do direito para o centro dos debates sobre a argumentação jurídica e a atividade normativa do poder judiciário. Ao sustentar sua teoria "imperativista" do direito, definindo uma prescrição jurídica como um comando dotado de autoridade e imposto pela vontade do soberano em uma comunidade política, Bentham se distancia da teoria 
jusnaturalista racionalista de Blackstone, que era inequivocamente dominante em seu tempo na Inglaterra, e abraça claramente as duas principais teses do positivismo jurídico contemporâneo: (a) a tese das fontes sociais, segundo a qual toda norma jurídica tem seu caráter determinado por suas fontes ou por sua origem, e (b) a tese da separabilidade entre direito e moral, segundo a qual o caráter jurídico de uma norma independe de sua correção moral (deixe-se de lado, para os fins da presente exposição, a questão de se a tese "b" está ou não incluída na tese "a"). Na opinião de H.L.A. Hart, a maior contribuição de Bentham à filosofia do direito teria sido a de "desmistificá-la", livrando-a dos elementos arbitrários e místicos da teoria jurídica que lhe precedeu. Hart não ressalta, porém, os aspectos políticos ou normativos da teoria jurídica de Bentham, e com isso não diferencia claramente a metateoria de Bentham da de seu principal pupilo, John Austin, que é visto por Hart como apenas um seguidor do pensamento de Bentham².

A leitura que Hart faz das teorias de Bentham e Austin não parece, sem embargo, inteiramente correta. Hart negligencia um dos elementos cruciais da teoria jurídica de Bentham, que se refere justamente à diferenciação estabelecida por Bentham entre os dois domínios da teoria jurídica: a expository jurisprudence, é dizer, a teoria jurídica expositória, à qual caberia meramente a descrição objetiva do direito positivo tal como ele é, ou seja, como um "fato social" a ser empiricamente verificado pelo teórico, e a censorial jurisprucence ou teoria jurídica censória, que busca encontrar racionalmente, com o auxílio do seu famoso princípio da utilidade, as regras jurídicas que deveriam ser estabelecidas por todos os sistemas jurídicos. A teoria jurídica "censória" é, como o próprio Bentham expressa, uma "teoria da legislação" que pretende servir de "modelo" para o legislador ao revelar os princípios políticos que mais se coadunam como o princípio da utilidade ${ }^{3}$.

A interpretação do projeto jurídico-teórico de Bentham que me parece mais apropriada é a de Postema, que, diferentemente de Hart, compreende Bentham como um positivista normativo ou prescritivo. Segundo essa leitura, o aspecto mais marcante da filosofia jurídica de Bentham está na teoria da legislação. Bentham 2 HART, H. L. A. Essays on Bentham. Oxford: OUP, 1982, esp. caps. 2 e 7.

3 A distinção aparece claramente formulada em BENTHAM, Jeremy. Of Laws in General (edited by HART, H. L. A.). London: Athlone Press, 1970. 
desenvolve a sua teoria do direito como parte de um projeto político que ele ambicionava por em prática. Neste projeto, Bentham pretendia simplesmente abolir o common law britânico, despindo-o de sua áurea mística e metafísica que supostamente Ihe atribuía um caráter racional e substituindo-o por um código civil a ser criado nos moldes do Código de Napoleão. Neste contexto, para Bentham, a teoria jurídica jusnaturalista e a linguagem apologética utilizada pelos juristas também tinham uma importante função política na sociedade aristocrática de seu tempo, pois se prestavam no mais das vezes a fornecer justificativas para uma postura conservadora e autoritária por parte dos juízes. Ele acreditava, portanto, que as teorias positivistas - que acatam as teses "das fontes sociais" e da "separabilidade entre o direito e a moral" - eram as únicas que poderiam oferecer uma concepção de juridicidade viável e respeitar o seu critério fundamental de racionalidade para um sistema jurídico, que consiste no princípio da utilidade 4 . O positivismo permitiria a construção de uma teoria que faz o conteúdo do direito não depender das preferências morais dos juízes e que é capaz de preservar o princípio da segurança jurídica e da certeza do direito, já que contém um critério objetivo para identificar o direito de forma clara.

A interpretação de Postema, em minha opinião, é de todas a mais coerente com a figura histórica de Bentham e com suas teses políticas e filosóficas. Seu positivismo jurídico, nesta perspectiva, é visto como extremamente coerente com sua filosofia utilitarista e com seu projeto de sociedade. Essa leitura tem, também, a virtude de esclarecer algumas importantes diferenças entre Bentham e Austin, que são negligenciadas nos escritos de filosofia do direito de H. L. A. Hart e da maior parte da doutrina. Embora os dois autores (Bentham e Austin) compartilhem a mesma descrição da natureza da norma jurídica e da autoridade do soberano, há uma diferença crucial entre eles. A "teoria da legislação" (censorial jurisprudence) praticamente desaparece em Austin. Este autor interpreta o princípio da utilidade, por exemplo, não no sentido revolucionário e reformista que Bentham originalmente utilizava (é dizer, como um instrumento racional para criticar as instituições vigentes e para propor reformas políticas), mas em um sentido diametralmente oposto. Austin adotava

4 POSTEMA, Gerald J. Bentham and the Common Law Tradition. Oxford: Clarendon, 1989. 
um utilitarismo teológico segundo o qual a vontade de Deus e o princípio da utilidade coincidiam, e o utilizava como uma descrição apologética do próprio common law e de práticas políticas com que Bentham jamais poderia compactuar. Em suma, Austin era politicamente conservador, e por isso a denominada censorial jurisprudence the era de muito pouca utilidade 5 . Por isso, nas páginas introdutórias de sua obra mais importante (The Province of Jurisprudence Determined), ele sustenta que "o objeto da teoria jurídica é o direito positivo, assim entendido de maneira simples e estrita: ou seja, o direito estabelecido por superiores políticos para os seus subordinados"6. Como se nota, a teoria do direito se tornava descritiva, analítica, despida de qualquer função normativa. Era apresentada como uma teoria apolítica, tão "pura" quanto a Teoria Pura do Direito de Hans Kelsen. A grande admiração que este autor alemão revelou por Austin decorre, portanto, do fato de Kelsen ter se identificado fortemente com as posições metateóricas do jurista inglês ${ }^{7}$.

\section{A RADICALIZAÇÃO DO POSITIVISMO DESCRITIVO NO PENSAMENTO DE HANS KELSEN}

É com Kelsen que o positivismo descritivo chega às suas formulações mais radicais. Influenciado, neste ponto específico, pelo ciclo de Viena e pelo positivismo lógico de seu tempo, Kelsen pretende, com sua Teoria Pura do Direito, construir uma teoria "livre de elementos estranhos ao método específico de uma ciência cujo único propósito é a cognição do Direito, e não a sua formação". É, pois, uma "ciência que precisa descrever o seu objeto tal como ele efetivamente é"8. Seu princípio metodológico fundamental é a pureza, que é vista como a única forma de "evitar 5 SCHOFIELD, Philip. Jeremy Bentham and Nineteenth-Century English Jurisprudence. Journal of Legal History, Vol. 12, n. 1, 1991, p. 58-88.

6 AUSTIN, John. The Province of Jurisprudence Determined. Londres: John Murray, 1832, p. 9. No original: "The matter of jurisprudence is positive law, simply and strictly so called: or law set by political superiors to political inferiors".

7 Ver: KELSEN, Hans. A Teoria Pura do Direito e a jurisprudência analítica. In: KELSEN, Hans. O que é Justiça?, trad. Luís Carlos Borges. São Paulo: Martins Fontes, 2001, p. 261283.

8 KELSEN, Hans. Teoria Geral do Direito e do Estado. Trad. Luís Carlos Borges. São Paulo: Martins Fontes, 1998, p. xxviii. 
um sincretismo metodológico que obscurece a essência da ciência jurídica e dilui os limites que Ihe são impostos pela natureza do seu objeto"9. Em seu propósito puramente descritivo, portanto, a teoria jurídica se desinteressa por questões práticas como a interpretação do direito e a fundamentação das decisões judiciais. As teses das fontes e da separabilidade, aqui, aparecem claramente não como o resultado de uma abordagem "interpretativa" ou construtiva em relação ao direito, e nem muito menos como uma opção justificada com base em argumentos políticos ou morais, mas como a aplicação de uma metodologia científica típica das ciências naturais, cujo rigor depende da neutralidade do teórico do direito e do isolamento de seu objeto de estudo, que deve ser claramente diferenciado de outros sistemas normativos com os quais ele eventualmente possa ter algum tipo de semelhança.

Kelsen rejeita, peremptoriamente, qualquer tentativa de se fundamentar uma "racionalidade prática" voltada para a fundamentação de normas e decisões sobre o que se deve ou não fazer. A razão, para ele, está limitada à nossa capacidade de "conhecer", que se contrapõe claramente à nossa "vontade", que é vista como o único locus onde se pode gerar a ação. Portanto, não faz qualquer sentido se tentar construir uma teoria geral da interpretação que almeje fornecer "métodos" ou "cânones" de interpretação, já que todos esses métodos são arbitrariamente escolhidos pelo intérprete autêntico do direito e levam invariavelmente a soluções contraditórias. A escolha entre as interpretações semanticamente permitidas para um documento normativo é, por conseguinte, um ato exclusivamente político, que se situa fora do objeto da ciência do direito.

\section{A VIRADA PARA O PONTO DE VISTA INTERNO NO PENSAMENTO DE HART (O PROBLEMA DE SUA INCONSISTÊNCIA COM O APPROACH DESCRITIVO)}

O positivismo descritivo, desde Austin a Kelsen, foi a teoria jurídica dominante ao longo de pelo menos a maior parte dos séculos XIX e XX, e exerceu um forte poder de sedução sobre o jurista que, ainda hoje, se situa no centro das discussões

9 KELSEN, Hans. Teoria Pura do Direito. Trad. João Baptista Machado. São Paulo: Martins Fontes, 2003, p. 2. 
jurídico-teóricas acerca da natureza e da validade do direito: o positivista Herbert Lionel Adolphus Hart. Nas páginas introdutórias de seu "O Conceito de Direito", Hart esclarece ao leitor que sua obra se insere na tradição analítica. Sua teoria jurídica é descrita como uma "sociologia descritiva" que busca explicar a norma jurídica como uma "norma social" cuja normatividade decorre da aceitação, por parte da comunidade jurídica e, em particular, dos agentes dotados de autoridade para aplicar o direito, de uma convenção básica (a regra de reconhecimento) acerca dos critérios fundamentais de validade para uma norma jurídica. Embora não se possa aqui aprofundar no pensamento deste importante teórico do direito, já que o objeto deste estudo é a "metateoria" do direito, e não as teses fundamentais acerca da natureza do direito, cabe um aparte sobre um ponto particular da teoria jurídica de Hart: a distinção entre o "ponto de vista interno" e o "ponto de vista externo", que são duas perspectivas a partir das quais se pode analisar o direito como prática social. Como explica Hart, é possível analisar as regras de um sistema normativo tanto como um mero observador externo que não as aceita, ele próprio, quanto como um "membro do grupo que as aceita e usa como guias para a sua conduta"10. Enquanto a primeira perspectiva pode ser denominada "externa", a segunda é o denominado "ponto de vista interno". Hart vê o sistema jurídico como um sistema de normas sociais, no duplo sentido de que essas normas "governam a conduta de seres humanos nas sociedades" e de que "elas devem a sua origem e existência exclusivamente a práticas sociais humanas"11. Essas práticas sociais, contudo, só existem em função da aceitação, pelos oficiais do direito que atuam no ponto de vista interno, de uma regra última de reconhecimento que contenha os critérios fundamentais de validade das outras regras que componham o sistema jurídico. Pode-se, de fato, dizer simplesmente que "o enunciado de que uma regra particular é válida significa que ela satisfaz todos os critérios providos pela regra de reconhecimento" ${ }^{12}$. E essa "regra de reconhecimento", como aponta o autor, existe apenas como "uma prática complexa, mas normalmente coerente, dos tribunais, oficiais e pessoas privadas ao identificar o direito por meio de certos critérios"13.

10 HART, H. L. A. The Concept of Law. 2. ed. Oxford: Clarendon, 1994, p. 89.

11 MACCORMICK, Neil. H. L. A. Hart, 2. ed. Sanford: Stanford University Press, 2008, p. 31.

12 HART, The Concept of Law, p. 103.

13 HART, The Concept of Law, p. 110-111. 
Vê-se, portanto, que o reconhecimento de uma regra por seus aplicadores é, para Hart, constitutivo para sua validade ${ }^{14}$. Sem embargo, esta virada para o "ponto de vista interno" consiste muito provavelmente em um primeiro passo para a autodestruição do positivismo descritivo, já que ela exige que o direito seja compreendido por meio de um tipo de pensamento que vai muito além das ambições "descritivistas" ou puramente "conceituais" de autores como Austin, Kelsen e o próprio Hart. A introdução do denominado "ponto de vista interno" traz sérias consequências para a teoria jurídica porque não mais é possível compreender o direito apenas como um observador externo que descreve certas regularidades e compila determinados comportamentos que são representados como meros "hábitos" de obediência. Para capturar, por exemplo, o sentido de um ato que se suspeita "ilícito" ou "delituoso" em um discurso jurídico, deve-se tentar entender "o que nós estaríamos fazendo se fôssemos a pessoa que realiza juízos de valor" sobre a sua validade, e tal compreensão não se dá apenas no nível da observação externa, mas no plano da investigação hermenêutica. Como explica MacCormick,

Temos que interpretar o sentido de tais juízos de valor do ponto de vista da pessoa que realiza esses juízos de valor ao invés de nos contentarmos com o ponto de vista de quem analisa este comportamento de fora. A introdução, por Hart, da ideia de um 'aspecto interno' na discussão das regras foi neste ponto preciso um avanço decisivo para a teoria jurídica analítica; como disse P. M. S. Hacker, ela envolveu a introdução de um método hermenêutico na teoria jurídica britânica ${ }^{15}$.

Essa leitura do ponto de vista interno, para nós, leva a se reconhecer uma "virada hartiana" na filosofia jurídica contemporânea, pois já não é mais possível

14 A noção de aceitação da regra de reconhecimento, no momento da sua aplicação, não implica, porém, a necessidade de que a massa da população de fato a aceite em sua inteireza. No pensamento de Hart, basta que os oficiais dotados de autoridade para aplicar o direito (principalmente os juízes) aceitem uma determinada regra de reconhecimento e que a massa da população tenha o hábito de obedecer às regras impostas por esses oficiais. Como explica Kenneth Himma, "para Hart, há um sistema jurídico S quando (1) os oficiais em $\mathrm{S}$ adotam a prática de se aceitar a regra de reconhecimento que define os critérios de validade e (2) os cidadãos em $\mathrm{S}$ geralmente seguem as regras de primeira ordem validadas por esses critérios". HIMMA, Kenneth Einar, Understanding the Relationship between the U.S. Constitution and the Conventional Rules of Recognition. In: ADLER, Matthew; HIMMA, K. Himma (Orgs). The Rule of Recognition and the U.S. Constitution. Oxford: Oxford University Press, 2007, p. 97.

15 MACCORMICK, H. L. A. Hart, p. 46, nossa tradução livre. 
compreender o direito com os métodos tradicionalmente empregados pelos positivistas. Ela convida a formular perguntas que estavam proscritas pelo rigorismo metodológico do positivismo descritivo, como a questão de se saber quando uma decisão que possa ser inferida das fontes do direito é "racional" ou razoável, ou quando se pode dizer que uma decisão está corretamente fundamentada. Como explica novamente MacCormick, essas perguntas são diuturnamente formuladas pelos juízes e demais operadores do direito que o manejam do ponto de vista interno, fazendo parte do leque de indagações que esses participantes do discurso jurídico naturalmente levantam em sua atividade prática ${ }^{16}$. Não obstante, nenhuma teoria adepta do positivismo descritivo jamais conseguirá oferecer uma resposta adequada a essas relevantes questões que são enfrentadas na argumentação jurídica.

Foi a virada para esse caráter hermenêutico da teoria jurídica que permitiu que Dworkin desferisse, em seu O Império do Direito, o golpe mais contundente sofrido pelo positivismo desde a sua consolidação na teoria jurídica de Jeremy Bentham. Sobre essa crítica metateórica de Dworkin a Hart se tratará nas linhas que se seguem.

\section{A CRÍTICA METATEÓRICA DE DWORKIN EM "O IMPÉRIO DO DIREITO" E A CONSOLIDAÇÃO DE UMA LEITURA HERMENÊUTICA DO DIREITO}

Dworkin leva o ponto de vista interno muito mais a sério do que Hart, e por isso consegue perceber todas as suas implicações para a filosofia do direito e sua relação com a prática jurídica. Ele introduz, nos três primeiros capítulos de sua grande obra, uma distinção entre as "proposições jurídicas", isto é, "os vários enunciados e pretensões que as pessoas fazem acerca do que o direito permite, proíbe ou lhes autoriza a ter", e os "fundamentos do direito", ou seja, as proposições mais gerais que fazem com que algo seja uma proposição jurídica. Os fundamentos do direito são as bases do direito; eles são as metaproposições

16 MACCORMICK, Neil. Legal Reasoning and Legal Theory. Oxford: Clarendon, 1978, p. 61-65. 
que "tornam uma proposição jurídica particular verdadeira"17.

Com esta distinção em mente, Dworkin se move para outra diferenciação. Juristas podem divergiremsuas atividades práticas de duas maneiras. De um lado, eles podem divergir sobre se os critérios de validade jurídica estabelecidos nos fundamentos do direito estão cumpridos em um caso particular (ou, numa linguagem hartiana, eles podem divergir sobre se determinados fatos e regras atendem aos critérios de identificação do direito estabelecidos na regra de reconhecimento); e, de outro lado, eles podem também divergir sobre os próprios fundamentos do direito, isto é, "sobre quais proposições, quando verdadeiras, tornam uma proposição jurídica verdadeira". O primeiro tipo de desavença é denominado "desavença empírica", ao passo que o último é denominado "desavença teórica"18.

A existência de desavenças teóricas cria um problema sério para o positivismo jurídico, já que elas parecem contradizer a ideia de que os critérios de validade são determinados por meras convenções sociais. Dworkin faz referência a desavenças teóricas precisamente porque ele acredita que as teorias positivistas do direito não oferecem mais do que um ponto de vista puramente fático (plain fact approach) ao direito e à filosofia do direito. Nesta ótica, o positivismo seria uma "teoria semântica", ou seja, uma teoria sobre o significado da palavra "direito", que imagina o direito como nada além de um fato social verificável. "Desavenças genuínas sobre o que seja o direito devem ser vistas como desavenças empíricas sobre a história das instituições jurídicas". A única diferença que se poderia encontrar entre as diferentes teorias positivistas do direito se refeririam a "quais fatos institucionais são cruciais" para solucionar desavenças empíricas ${ }^{19}$.

Já que os juízes e os juristas práticos muitas vezes discordam sobre questões teóricas, Dworkin diria, então, que deve ser verdadeiro não apenas que o direito é uma prática interpretativa, mas também que a teoria jurídica em si mesma é "interpretativa", em vez de "semântica", e que não há uma linha clara entre a filosofia do direito e os argumentos jurídicos práticos: "nenhuma linha firme divide a teoria jurídica da aplicação do direito ou qualquer outro aspecto da prática jurídica"20.

17 DWORKIN, Ronald. Law's Empire. Cambridge, MA: Belknap, 1986, p. 4-5.

18 DWORKIN, Ronald. Law's Empire, p. 5.

19 DWORKIN, Ronald. Law's Empire, p. 33.

20 DWORKIN, Ronald. Law's Empire,p. 90. 
Por uma teoria interpretativa se entende, aqui, uma teoria que adota uma "atitude interpretativa" em relação à prática social que ela procura compreender. Essa atitude tem, segundo a perspectiva hermenêutica de Dworkin, dois componentes. "O primeiro é a premissa de que essa prática... não apenas existe, mas possui um valor, ou seja, que ela serve a algum propósito ou interesse ou avança algum princípio - é dizer, que ela tenha um fim - que pode ser enunciado independentemente da mera descrição das regras que compõem essa prática". O segundo, por seu turno, é a premissa adicional de que as suas regras "não são necessariamente ou exclusivamente o que elas sempre foram consideradas como sendo, mas são, pelo contrário, sensíveis a este fim ou propósito"21. Uma teoria interpretativa do direito, portanto, é uma teoria que interpreta o direito à luz de seu propósito, à luz de sua função ou justificativa política e seus princípios fundamentais.

Mesmo o positivismo de Hart, segundo a perspectiva de Dworkin, poderia ser relido como uma teoria interpretativa, passando a ser compreendido não mais como uma teoria semântica acerca da "coisa" ou da "palavra" direito, ou ainda sobre os critérios de identificação do direito, mas como uma teoria que entende o direito como composto por convenções sociais ou acordos sobre determinadas regras ou decisões políticas tomadas no passado, e que defende que ele deve ser construído e interpretado apenas segundo essas convenções, e não também segundo as justificativas politicomorais dessas convenções (como o faz, por exemplo, a concepção defendida pelo próprio Dworkin, que ele denomina "Direito como Integridade").

Sem embargo, Hart não se deu por convencido por essas objeções metateóricas de Dworkin, e insistiu, no posfácio à segunda edição de sua obra, na asserção de que sua teoria é "descritiva, no sentido de que ela é moralmente neutra e não possui qualquer propósito justificatório"22. Hart reafirma, portanto, de modo enfático, o positivismo descritivo que havia defendido na formulação inicial de sua teoria. Ele sustenta que a sua teoria jurídica almeja ser uma teoria geral do direito, e não uma teoria da decisão jurídica ou da interpretação do direito, já que carece de pretensões normativas ou práticas como a de Dworkin. Interpreta a sua própria teoria, portanto, como uma teoria "conceitual" cujo propósito é descrever a "natureza" ou a "essência" do direito. 
Hart encontra, ainda hoje, vários juristas na tradição positivista que ainda pretendem compreender a teoria jurídica desta forma, como, por exemplo, Shapiro, que anuncia nas páginas iniciais de seu Legality que o seu projeto de pesquisa está menos preocupado com a teoria jurídica normativa (normative jurisprudence) do que com a teoria jurídica analítica (analytical jurisprudence). Enquanto a primeira "lida com os fundamentos morais do direito", a última "examina seus fundamentos metafísicos". Ele acredita que sua teoria jurídica é uma investigação acerca da "natureza fundamental do direito"23. Nesse sentido, sua teoria jurídica pretende ser uma espécie de "ontologia social", é dizer, um ramo da filosofia analítica que estuda a natureza de entidades que pertencem à realidade social. A questão principal a ser respondida por esta investigação é a questão "O que é direito?", que deve ser claramente diferenciada da questão "Qual é o direito?", já que está preocupada com "a natureza do direito em geral", em vez de com qualquer sistema jurídico específico ${ }^{24}$.

Sem embargo, nem Hart nem Shapiro parecem ter clareza sobre as implicações metateóricas de suas próprias teorias, já que por trás da pretensa neutralidade de uma análise puramente "analítica" ou "conceitual" há inevitáveis elementos normativos que foram muito bem capturados por Dworkin em sua réplica ao posfácio de Hart, no qual se demonstrou que nenhuma teoria jurídica é valorativamente neutra e desengajada porque o direito é uma prática social de natureza argumentativa, a qual só pode ser compreendida da perspectiva do participante. Para Dworkin, "qualquer teoria do direito, incluindo-se o positivismo, é baseada no fim das contas em alguma teoria política normativa"25. Nesse sentido, Dworkin parece estar certo ao afirmar que "o direito é um conceito controvertido" e, como tal, é um conceito que "deriva o seu sentido de seu uso" ou dos "contextos de debates acerca do que o direito é" 26.

Nesse sentido, apesar de Hart ter acreditado que sua teoria fosse puramente conceitual, ele não conseguiu livrar sua investigação de argumentos de moralidade política. Há vários exemplos que ilustram esse ponto. Primeiramente, como já se viu, 23 SHAPIRO, Scott. Legality. Cambridge, MA: Belknap, 2011, p. 8.

24 SHAPIRO, Scott. Legality. p. 7.

25 DWORKIN, Ronald, A Reply. In: COHEN, Marshall (Ed.). Ronald Dworkin and Contemporary Jurisprudence. Londres: Duckworth, 1984, p. 254.

26 DWORKIN, A Reply, p. 256. 
a própria noção de "ponto de vista interno" exige que o teórico do direito ponha a si próprio na perspectiva do aplicador do direito (a perspectiva interna) se ele quiser ter acesso ao contexto em que os conceitos jurídicos são empregados. Em segundo lugar, o argumento central de Hart na defesa de sua tese de que o direito não deve ser formado apenas por regras primárias (de conduta), mas também por "regras secundárias" que se ocupam das próprias regras primárias, está fundado em uma reductio ad absurdum, que expõe claramente as deficiências de uma organização política que use apenas o primeiro tipo de regras. Uma sociedade imaginária em que houvesse apenas regras primárias de obrigação sofreria dos problemas da "incerteza", pois não haveria um procedimento para solucionar dúvidas sobre a validade de uma regra; de seu "caráter estático", pois não haveria meios, em tal sociedade, para adaptar essas regras a novas circunstâncias, modificando-as ou introduzindo novas regras; e da "ineficiência", já que não haveria um processo para manter a pressão social difusa por meio das quais as regras são aplicadas e mantidas ${ }^{27}$. É precisamente por causa disso que se precisa de regras secundárias para prover um antídoto para esses três sérios problemas para qualquer sociedade. Sem embargo, como Dworkin aponta corretamente, essa construção está longe de ser neutra ou puramente conceitual, como quer Hart.

Se Dworkin estiver certo neste ponto, então a defesa de Hart da neutralidade da teoria jurídica é inconsistente com a sua própria teoria, pois a escolha de sua posição teórica é determinada por considerações políticas e morais.

E o mesmo vale, também, para a Teoria do Direito como Planejamento, de Scott Shapiro, que no fundo é uma espécie de positivismo normativo, como se teve a oportunidade de demonstrar em recente resenha publicada à sua obra ${ }^{28}$. Tal como a teoria de Hart, a de Shapiro "não é uma descrição neutra da prática jurídica, mas uma interpretação dela que pretende não apenas descrevê-la como justificá-la - demonstrar porque esta prática é valiosa e como ela deve ser conduzida de modo a proteger e fomentar esse valor"29.

Neste ponto, ao menos, não se pode deixar de concordar com Dworkin quando este sustenta que "filosofias Arquimedianas" que "analisam de fora, de cima para 27 HART, H. L. A. The Concept of Law, 92-93.

28 BUSTAMANTE, Thomas. Legality, by Scott Shapiro (Book Review). Legal Studies - The Journal of the Society of Legal Scholars, vol. 32, n. 3, 2012, p. 499-507.

29 DWORKIN, Ronald. Justice in Robes. Cambridge, MA: Belknap, 2006, p. 141. 
baixo, a moralidade, a política, o direito, a ciência e a arte" ${ }^{30}$ são inadequadas para entender conceitos políticos como justiça, democracia e direito, já que elas "ignoram o modo como conceitos políticos de fato funcionam nos argumentos políticos" 31 . Quando um filósofo define um conceito político, ele está "tomando partido", é dizer, ele está erigindo "pretensões normativas" sobre o conteúdo de tal conceito e o papel que ele deve desempenhar em argumentações políticas. Isso ocorre, para Dworkin, porque conceitos políticos não são "entidades naturais" cuja existência e conteúdo independam da invenção ou das crenças de quem quer que seja32. Enquanto a "estrutura profunda de entidades naturais é física", a de "valores políticos não é física, mas normativa"33. Teorias jurídicas são, portanto, diferentes "concepções de juridicidade" que pretendem estar corretas quando o valor da "juridicidade" (legality) ou o "Estado de direito" (rule of law) são aplicados como argumentos políticos.

Como Dworkin demonstra em seu comentário ao posfácio de Hart, todas as diferentes visões da teoria jurídica "representam uma aderência comum ao valor da juridicidade", apesar de com diferentes concepções acerca do que a juridicidade seja. "Concepções de juridicidade diferem... acerca de quais tipos de standards são condições suficientes para satisfazer a juridicidade e de que modo esses standards devem ser estabelecidos com antecedência; pretensões de direito são pretensões sobre quais standards do tipo correto de fato foram estabelecidos de modo correto"34.

A Teoria do Direito como Planejamento, de Shapiro, por exemplo, é uma defesa de uma concepção de juridicidade que pretende que o propósito fundamental do sistema jurídico é evitar a deliberação moral por meio de planos identificáveis que predeterminam juízos de valor do povo e dos oficiais do direito que estão encarregados da aplicação do direito. Éjustamente porque a prática social "direito" é sensível a este propósito que Shapiro acredita, como os positivistas exclusivos, que o direito há de ser determinado apenas por fatos sociais.

30 DWORKIN, Ronald, Justice in Robes, 141.

31 DWORKIN, Ronald, Justice in Robes, 148.

32 DWORKIN, Ronald, Justice in Robes, 154.

33 DWORKIN, Ronald, Justice in Robes, 155.

34 DWORKIN, Ronald, Justice in Robes, 170. 
Essas conclusões permitem que o leitor se aproxime da tese central deste ensaio, que consiste na afirmação de que o positivismo jurídico, hoje, só pode sobreviver se ele assumir a forma de um positivismo normativo no sentido de autores como Waldron ou Campbell, que entendem o caráter da teoria jurídica no mesmo sentido em que Dworkin a compreende.

\section{CONSIDERAÇÕES CONCLUSIVAS: A IMPLOSÃO DO POSITIVISMO DESCRITIVO E O RENASCIMENTO DO POSITIVISMO NORMATIVO DE INSPIRAÇÃO EM BENTHAM}

O positivismo de autores como Frederick Schauer, Tom Campbell e Jeremy Waldron se apresenta como reconhecidamente "neobenthamista", no sentido de que esses autores fundamentam o seu positivismo em uma tese normativa, fundada em razões de natureza política e moral acerca de como o direito deve ser construído pelo intérprete ${ }^{35}$. O "positivismo normativo" pode ser entendido como um tipo de positivismo jurídico que inicia com um argumento moral em defesa de sua própria concepção de juridicidade.

De acordo com o positivismo normativo ou prescritivo, "inicia-se com uma descrição normativa da missão do direito", e depois, "argumenta-se que esta missão não pode ser realizada a não ser que regras, comandos, normas, editos ou planos sejam reconhecidos como direito com base em critérios não-morais" 36 . 35 Nesse sentido ver: SCHAUER, Frederick, Positivism as Pariah. In: GEORGE, Robert P. (Org.).

The Authonomy of Law - Essays on Legal Positivism. Oxford: Clarendon, 1996; WALDRON, Jeremy, Normative (or Ethical) Positivism. In: COLEMAN, Jules (Ed.). Hart's Postscript:

Essays on the Postscript to "The Concept of Law". Oxford: OUP, 2001. WALDRON, Jeremy, Can There be a Democratic Jurisprudence?. Emory Law Journal, vol. 58, 2009, p. 675-712; CAMPBELL, Tom. The Legal Theory of Ethical Positivism. Aldershot: Ashgate, 1996; CAMPBELL, Tom. Prescriptive Legal Positivism: Law, Rights and Democracy. Londres: UCL Press, 2004. A ideia central do positivismo prescritivo, ético ou normativo é a de que há razões morais (e, por que não, políticas) para a formulação de um critério amoral de identificação do direito válido. Nesse sentido, veja-se a explicação de MACCORMICK, Neil, A Moralistic Case for A-moralistic Law?. Valparaiso University Law Review, vol. 20, 1985 , p. 1-41. Contra a opinião majoritária, no entanto, o autor deste ensaio sustenta que o pensamento jurídico de MacCormick não apenas evoluiu claramente para uma forma de póspositivismo, mas também sempre conteve certos elementos que não o deixavam confortável dentro da tradição positivista. Ver: BUSTAMANTE, Thomas, Comment on Petroski: On MacCormick's Post-Positivism. German Law Journal, vol. 12, n. 2, 2011, p. 693-727.

36 WALDRON, Jeremy, Planning for Legality (Review Essay). Michigan Law Review, vol. 109,2011, p. $883,894$. 
Como Waldron assentou de modo claro, "a pretensão dos positivistas normativos é de que os valores associados ao direito - a juridicidade e o estado de direito, em um sentido amplo - podem ser melhor alcançados se a operação ordinária de tal sistema não exigir que as pessoas realizem valorações morais para se saber o que o direito é" 37 . Portanto, positivistas prescritivos como Waldron ou Campbell buscam "reabilitar" o positivismo ao enfatizar os "fortes aspectos normativos" de suas teses principais. O positivismo é visto como "fortemente motivado por certos valores morais e preocupações políticas" que não são de forma alguma incompatíveis com as teses fundamentais do positivismo jurídico ${ }^{38}$.

O positivismo normativo, por esta razão, resiste em aceitar o paradigma do "direito positivo versus direito natural". Ele inicia o seu argumento com uma tese moral e, depois, como resultado da veracidade da ideia moral que é definida como o propósito do direito, e tira inferências positivistas sobre como o direito há de ser estabelecido ou como a argumentação jurídica há de ser conduzida: "Se a dicotomia entre positivismo e direito natural tiver de ser abandonada, que seja assim"39.

A diferença chave entre, de um lado, o positivismo normativo ou prescritivo e, de outro lado, o positivismo neutro ou descritivo, parece ser que o primeiro não está comprometido com qualquer forma de positivismo lógico ou filosófico. Ele não pretende ser neutro e nem sustenta, também, que está apenas identificando uma suposta "essência" ou um "truísmo" sobre a natureza do direito, como Kelsen tenta fazer quando ele aduz que sua teoria do direito é "purificada de toda ideologia política"40 ou quando Hart diz que sua teoria "não pretende justificar" ou aprovar com base em fundamentos morais às regras, às formas e às estruturas de um sistema jurídico ${ }^{41}$.

O positivismo jurídico contemporâneo, já distanciado do positivismo filosófico e do modelo de ciências naturais, retoma a sua feição original expressa nas ideias políticas de Bentham, que fundamentava essa doutrina no valor moral de princípios como a previsibilidade e a segurança jurídica. Nesse sentido, 37 WALDRON, Jeremy. Normative (or Ethical) Positivism, p. 421.

38 CAMPBELL, Tom. Prescriptive Legal Positivism, p. 5.

39 WALDRON, Jeremy. Normative (or Ethical) Positivism, p. 418.

40 KELSEN, Hans. Introduction to the Problems of Legal Theory, Trans. Bonnie Litschewski Paulson and Stanley L Pauson. Oxford: OUP, 1992, p. 1.

41 HART, H. L. A. The Concept of Law, p. 240. 
mais contemporaneamente, Campbell e Waldron sustentam que o positivismo jurídico deve ser adotado porque eles não acreditam que o princípio do Estado de Direito (ou o valor da "juridicidade") permita que o juiz possa, ele próprio, realizar valorações morais sobre questões éticas fundamentais que repercutem sobre toda a sociedade. Trata-se, portanto, de uma interpretação construtiva do princípio do Estado de Direito e das competências institucionais do poder judiciário segundo a qual não está o juiz autorizado a realizar valorações morais "em nome de toda a sociedade"42, pois o parlamento estaria, nas sociedades democráticas, em condições muito melhores de tomar este tipo de decisão.

O positivismo normativo, como se percebe claramente, torna o positivismo jurídico uma teoria muito mais interessante do que a sua alternativa "descritiva" ou puramente "conceitual", que, em busca da objetividade científica e de um rigor metodológico absoluto, pagava o alto preço de se tornar uma teoria irrelevante e distanciada da prática jurídica. Uma teoria, segundo Dworkin, "desinteressante", pois separada da argumentação jurídica e dos contextos de aplicação do direito. 0 positivismo normativo, assim como o não positivismo de autores como Dworkin, Alexy e o último MacCormick, não aceita claramente a dicotomia entre "teoria do direito" e "teoria da decisão jurídica", pois ele entende que faz parte da teoria do direito explicar como a argumentação jurídica é realizada e deve se realizar. Ele passa a ser uma teoria tão interessante quanto essas teorias não positivistas, que procuram estabelecer uma conexão entre a teoria do direito e a teoria da argumentação jurídica. Ele passa a influir, portanto, no raciocínio jurídico e a ser, ele próprio, uma postura interpretativa diante do direito. Ele se transforma, também, em uma teoria interpretativa do direito.

Isso implica, porém, o ocaso do positivismo descritivo. Esta teoria, que tinha a pretensão essencialista de estar revelando "verdades filosóficas"43 sobre o direito ou realizando uma "ciência" rigorosa e dotada de um status superior sobre as demais formas de conhecimento jurídico, é substituída por uma versão de positivismo que é tão hermenêutica e engajada moralmente quanto as teorias não positivistas como o modelo de Direito como Integridade, de Dworkin, e as

42 WALDRON, Jeremy. Judges as Moral Reasoners. International Journal of Constitutional Law 7 (2), 2009, p. 2-24.

43 SHAPIRO, Legality, p. 275. 
teorias pragmatistas norte-americanas. Desde a denominada "virada linguística" e da ascensão do ponto de vista hermenêutico na filosofia do direito já não há mais lugar para qualquer abordagem puramente descritiva do direito. Este talvez seja, aliás, um dos primeiros passos para se superar, definitivamente, o desgastado paradigma de contraposição irreconciliável entre positivismo e jusnaturalismo no âmbito da filosofia do direito.

\section{REFERÊNCIAS}

AUSTIN, John. The Province of Jurisprudence Determined. Londres: John Murray, 1832.

BENTHAM, Jeremy. Of Laws in General (edited by H. L. A. Hart). London: Athlone Press, 1970.

BUSTAMANTE, Thomas, Comment on Petroski: On MacCormick's Post-Positivism. German Law Journal, vol. 12, n. 2, 2011, p. 693-727.

BUSTAMANTE, Thomas. Legality, by Scott Shapiro (Book Review). Legal Studies - The Journal of the Society of Legal Scholars, vol. 32, n. 3, 2012, p. 499-507.

CAMPBELL, Tom. Prescriptive Legal Positivism: Law, Rights and Democracy. Londres: UCL Press, 2004.

CAMPBELL, Tom. The Legal Theory of Ethical Positivism. Aldershot: Ashgate, 1996.

DWORKIN, Ronald. A Reply. In: COHEN, Marshall Cohen (Ed.). Ronald Dworkin and Contemporary Jurisprudence. Londres: Duckworth, 1984.

DWORKIN, Ronald. Justice in Robes. Cambridge, MA: Belknap, 2006.

DWORKIN, Ronald. Law's Empire. Cambridge, MA: Belknap, 1986.

HART, H. L. A. Essays on Bentham. Oxford: OUP, 1982.

HART, H. L. A. The Concept of Law. 2. ed. Oxford: Clarendon, 1994.

HIMMA, Kenneth Einar. Understanding the Relationship between the U.S. Constitution and the Conventional Rules of Recognition. In ADLER, Matthew; HIMMA, K. (Orgs.). The Rule of Recognition and the U.S. Constitution. Oxford: Oxford University Press, 2007.

KELSEN, Hans. Introduction to the Problems of Legal Theory, Trans. Bonnie Litschewski 
Paulson and Stanley L Pauson. Oxford: OUP, 1992.

KELSEN, Hans. A Teoria Pura do Direito e a jurisprudência analítica. In. Kelsen, Hans, O que é Justiça? São Paulo: Martins Fontes, 2001, p. 261-283.

KELSEN, Hans. Teoria Geral do Direito e do Estado. Trad. Luís Carlos Borges. São Paulo: Martins Fontes, 1998.

KELSEN, Hans. Teoria Pura do Direito. Trad. João Baptista Machado. São Paulo: Martins Fontes, 2003.

MACCORMICK, Neil. A Moralistic Case for A-moralistic Law? Valparaiso University Law Review, vol. 20, 1985, p. 1-41.

MACCORMICK, Neil. H. L. A. Hart. 2. ed. Sanford: Stanford University Press, 2008, p. 31.

MACCORMICK, Neil. Legal Reasoning and Legal Theory. Oxford: Clarendon, 1978.

POSTEMA, Gerald J. Bentham and the Common Law Tradition. Oxford: Clarendon, 1989.

SCHAUER, Frederick. Positivism as Pariah. In: GEORGE, Robert (Org.). The Authonomy of Law - Essays on Legal Positivism. Oxford: Clarendon, 1996.

SCHOFIELD, Philip. Jeremy Bentham and Nineteenth-Century English Jurisprudence. Journal of Legal History, Vol. 12, n. 1, 1991, p. 58-88.

SHAPIRO, Scott. Legality. Cambridge, MA: Belknap, 2011.

WALDRON, Jeremy. Can There be a Democratic Jurisprudence? Emory Law Journal, vol. 58, 2009, p. 675-712.

WALDRON, Jeremy. Normative (or Ethical) Positivism. In: COLEMAN, Jules (Ed.). Hart's Postscript: Essays on the Postscript to “The Concept of Law". Oxford: OUP, 2001.

WALDRON, Jeremy. Planning for Legality (Review Essay). Michigan Law Review, vol. 109, 2011 , p. 883, 894.

WALDRON, Jeremy. Judges as Moral Reasoners. International Journal of Constitutional Law 7 (2), 2009, p. 2-24. 